\title{
Energy Efficient Secured Device Control using IOT
}

\author{
M. Srilatha ${ }^{1}$, V. H. P. Bhargava ${ }^{2}$, A. R. Sridhar ${ }^{3}$, P. Sainag ${ }^{4}$, CH. Madhukar ${ }^{5}$ \\ ${ }^{1}$ Assistant Professor, Department of ECE, Vardhaman College of Engineering, India, ma_srilatha2@ yahoo.co.in \\ ${ }^{2}$ Student, Department of ECE, Vardhaman College of Engineering, India, bhargava97varanasi@ gmail.com \\ ${ }^{3}$ Student, Department of ECE, Vardhaman College of Engineering, India, arsridhar520@ gmail.com \\ ${ }^{4}$ Student, Department of ECE, Vardhaman College of Engineering, India, sainagparshi@ gmail.com \\ ${ }^{5}$ Student, Department of ECE, Vardhaman College of Engineering, India, madhumadhu71653@ gmail.com
}

\begin{abstract}
Availability of internet everywhere made us easy to advance in IoT and made it as a primary application in this advancing technology. Using this technology, Users can access devices remotely. Energy economical secured device management is proposed in this paper, where all the appliances and meters can admittance remotely. In proposed system, web-based device is hooked up to the most offer unit (meter) of the power unit system which can be monitored and retrieved information using web. Additionally, camera and motion detector devices are used for security purpose whose status will be notified with e-mail and SMS. For wireless property, the static science address is employed.
\end{abstract}

Proposed system automation relies on the multiple applications in which one mode is voice recognition and the other is web-based application in the browser. Ultimately, the aim is to form devices safer and more intelligent than any other previous existing system.

Key words: Device control, Intrusion detection, Internet of Things, Voice Assistance.

\section{INTRODUCTION}

Due to the development in technology, interaction between users and machines has become more realistic and easier in their regular life's. Now a days, user-machine interaction analysis was tremendously increased due to IOT. The major objective of this technology is to access the devices connected remotely using the web.

The applications using IoT aren't restricted to specified field, but usage has expanded to numerous fields. Even though a lot of improvement has been achieved in all fields using IOT, however reducing the consumption of power is still a major universal problem. According to the latest reports, ICT tools alone uses almost $4.7 \%$ of the world's electricity, which can probably even more increases

\section{LITERATURE REVIEW}

There are many devices which are primarily managed by phones or tablets [1] and also many devices have their own features which use home automation as main method. But cannot address issues like deficiency of user-friendly interface, high security systems etc [2]-[10]. Author in [11] modelled IoT project which gives alarm when anyone pass the way and the micro controller utilized for this model is TICC3200 launching pad board. Micro controller which is connected to internet starts sending alerts regardless of the user connected to the internet or not [14], [24] but unable to give clear information of unauthorized user. [12]-[13] uses motion detectors and cameras which are controlled by Raspberry pi. Different controllers are used for controlling the motion of various sensors which will help to police department (CVT) [15]. [16]-[20] describes different models of IoT and networks which are currently helping the researchers to develop more about Internet of things. Different implementation techniques [21]-[23] are explained which are efficient in the field of IoT.

\section{IMPLEMENTATION AND DESIGN}

One of the main inputs given to machine is audio or speech. Here, user uses voice interaction to make the system operate. This can be possible with the voice assistant through Bluetooth. If we use multiple input methods to give commands to system, creates confusion and disturbance. Also, voice quality reduces resulting in wrong outputs. To avoid such a type of situation a web-based dashboard is used in proposed method, where in controlling of various devices will be done using buttons present on dashboard remotely. Figure 1 shows the block diagram of the proposed system.

\subsection{Raspberry-pi}

Raspberry pi as shown in Figure 2 is a powerful minicomputer which is a quad core processor. It can be used with keyboard and mouse and can be programmed in the terminal. It has USB ports, Ethernet controller, audio out, camera adapter, 


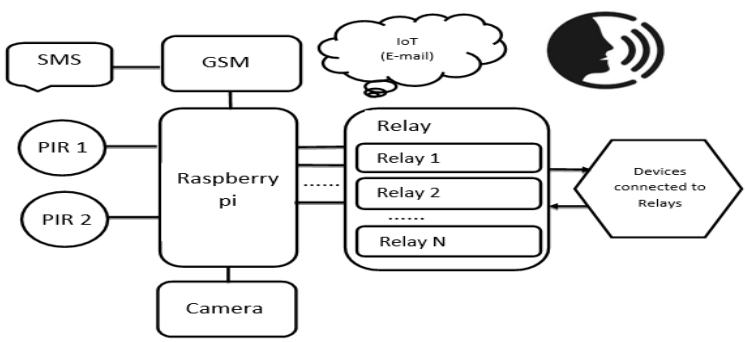

Figure 1: Block diagram of the proposed system

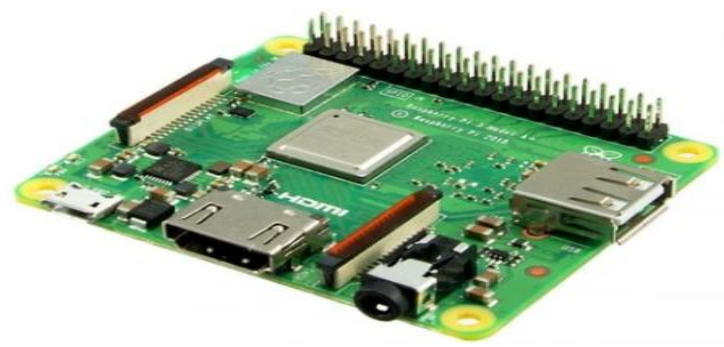

Figure 2: Raspberry-pi

HDMI port and various other ports. It is evolved with various versions as model $\mathrm{B}$ and $\mathrm{B}+$, also we have $\mathrm{A}$ and $\mathrm{A}+$ versions. BCM2835 SoC is used with 1st generation chip and has various levels of cache as L1, L2. It has operating system like Raspbian OS and also it supports various other operating systems. It can be connected to internet using Wi-Fi, ethernet and has various general purpose and special purpose input output connectors.

\subsection{Global System for Mobile (GSM)}

European Telecommunications Standard Institute developed a GSM as shown in Figure 3 which can be used by all customers. It is designed to know the protocols developed for $2 \mathrm{G}$ digital cellular networks that is employed in mobile devices. Initially, it is installed in Suomi in December 1991 and then for mobile communications, it has become a world customary by the mid-2010s.

\subsection{PIR Module}

This sensor as shown in Figure 4 is used to sense the motion of an object depends on infrared radiation. A PIR sensor will be small in size, usage of power consumption is low, cost is less and easy to handle. Due to this reasons PIR sensor is used in most of the appliances which are used for household purpose and business purpose.

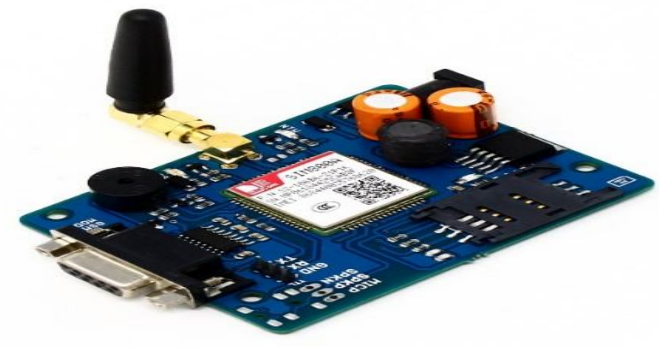

Figure 3: GSM Module

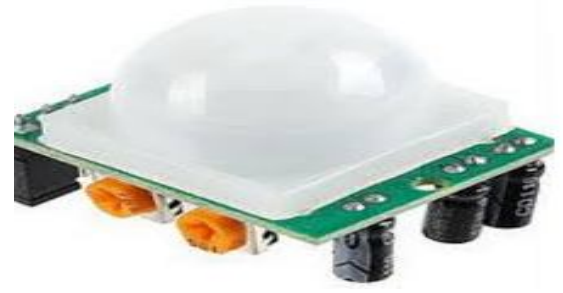

Figure 4: PIR Module

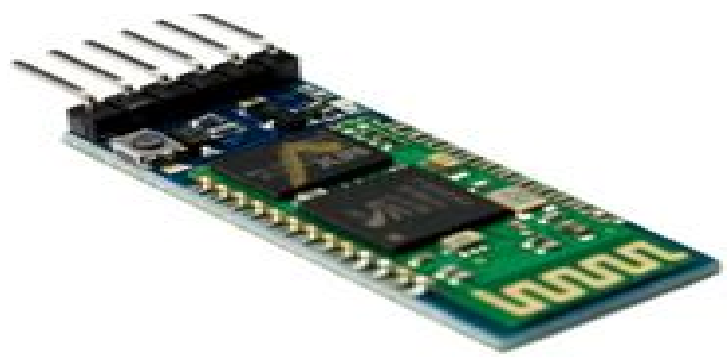

Figure 5: Bluetooth Module

\subsection{Relay}

Electrically operated switch is relay. There are many input terminals and operation contact terminals for one or many signals. There can be any type of different contacts for example: create contact, or break contact or even mixture of them.

\subsection{Bluetooth Module}

To communicate between devices, Bluetooth uses serial communication. The device is meant for communicating wirelessly and depends on transmitter and receiver the communication range will be less than 100 meters. The Bluetooth module as shown in Figure 5 can be operated either as a master or slave. The role of the master will issue the commands and factory setting is done by the slave module. Slave module only accepts connections. Master can initiate connections unlike the slave module. It can be used to establish connection between MCU and GPS.

Main controller unit connected with the WI-FI network implements the connection of the smart home. All the devices which are not smart like subunits are connected to turn into smart appliance. Therefore, the smart homes can be accessed using Bluetooth to maintain the communication and also by voice and web assistant.

Raspberry Pi module is used to interface various components like GSM, PIR sensor and camera as shown in figure 1. Various relay modules control all the devices and main relay module which is password protected is used to control all the relays hence used for security purpose. Whenever motion is detected in the gate/laboratory, camera turns ON and an SMS will be sent to mobile. Also captured photo is sent through E-Mail. Hence the Raspberry Pi is connected to the internet, we can control devices using IoT by dashboard. 


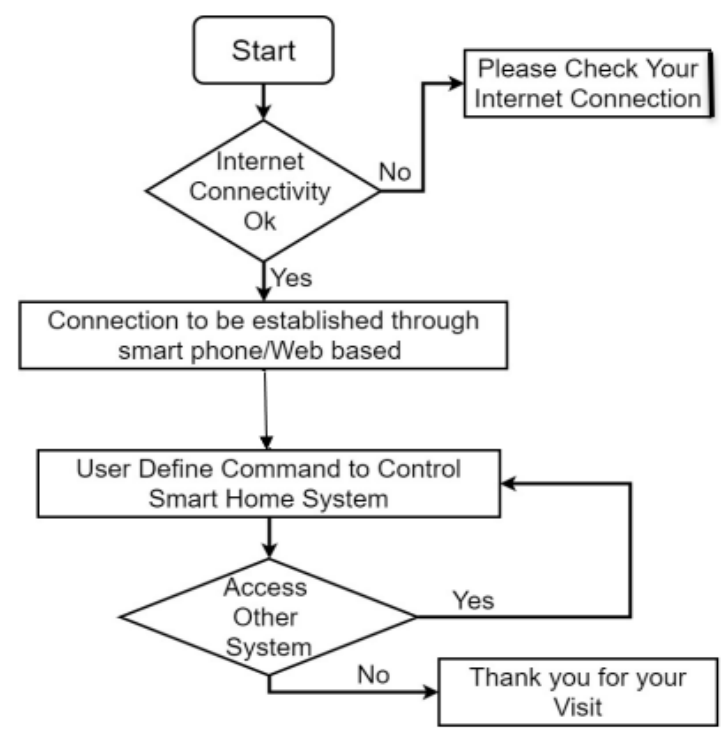

Figure 6: Flowchart of the proposed system

Also, Bluetooth is used to control the devices by using voice. We can pass various commands to the Raspberry-pi like "System ON", "System OFF", "Server ON", "Server OFF", "All ON", "All OFF". Each device can be controlled individually as well as at once.

Whenever an unauthorized person enters the area, the PIR sensor detects the person and image will be captured and sent to the registered E-mail using GSM module. Process flow is shown in Figure 6.

\section{RESULTS AND DISCUSSIONS}

Any device which seems data confidential is provided with more security and can be accessed from anywhere around the world using web-based dashboard and voice assistant. Web based dashboard is shown in below Figure 7 .

Once the creation of dashboard is done, all the devices can control using Raspberry pi and can turn the devices ON/OFF or all at once. Dashboard can be accessed using IP address which is known to owner and shows one of the security features for devices.

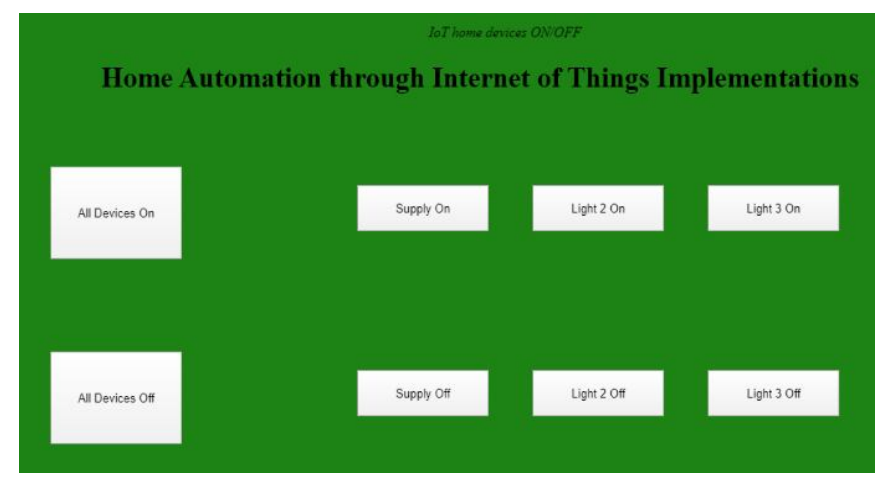

Figure 7: Dashboard

\subsubsection{7 - PuTTY}

pi@raspberrypi: /project \$ sudo python home.py Welcome to Smart Home Automation System

Figure 8: Welcome Screen

First user will login to the Raspberry pi using login ID as "pi" and password as "raspberry", then a screen will open saying Welcome to Home Automation System as shown in Figure 8.

When a person enters the area then the external PIR sensor detects the person saying Capturing photo and sends the Email as shown in below Figure 9. Later SMS will also be sent to the registered mobile number as shown in below Figure 10.

Whenever person forcefully enters the room or area then an internal PIR sensor detects the person and sends SMS saying person in room as shown in below Figure 11.

Till now how to provide security to home or office has been done and now comes the control of devices using dashboard and Bluetooth. AMR Voice control app is used to connect to Raspberry pi and control the devices connected to the pi as shown in below Figure 12. Now pressing the mic button in app, various controls can be issued by user to control the devices as shown in Figure 13.

\subsubsection{7 - PuTTY}

pi@raspberrypi: /project \$ sudo python home.py

Welcome to Smart Home Automation System

Person entered alert!

Subprocess call webcam.sh

**Capturing Photo.....

**********Email Sending*************

Subprocess call mail.py

**********Email Sent*************

Figure 9: Sending Email

\subsubsection{7 - PuTTY}

pi@raspberrypi: /project $\$$ sudo python home.py

Welcome to Smart Home Automation System

Person entered alert!

Subprocess call webcam.sh

***apturing Photo....

$* * * * * * * * * *$ Email Sending $* * * * * * * * * * * *$

Subprocess call mail.py

**********Email Sent************

$* * * * * * * * *$ SMS Sending************

Reading Mobile number.....

Writing message

$* * * * * * * * * * \operatorname{SMS} S \operatorname{Sent} * * * * * * * * * * * *$

Figure 10: Sending SMS on External PIR detection 


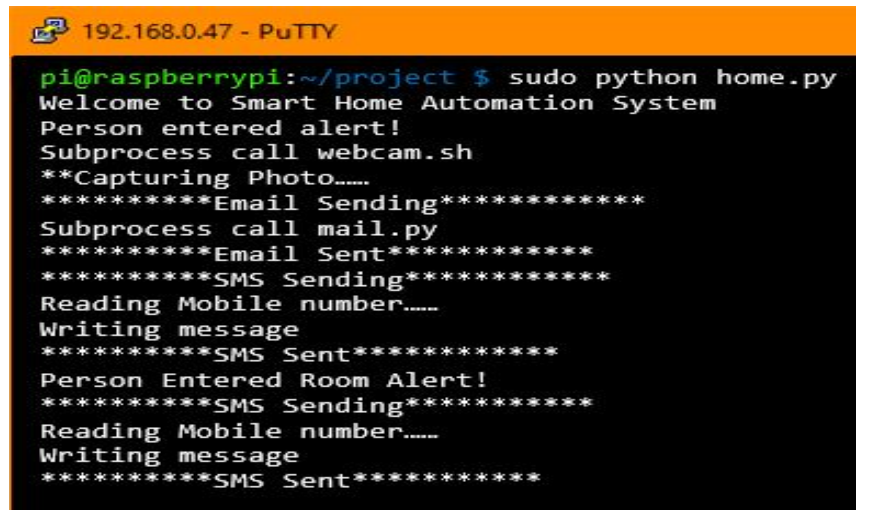

Figure 11: Sending SMS on Internal PIR detection

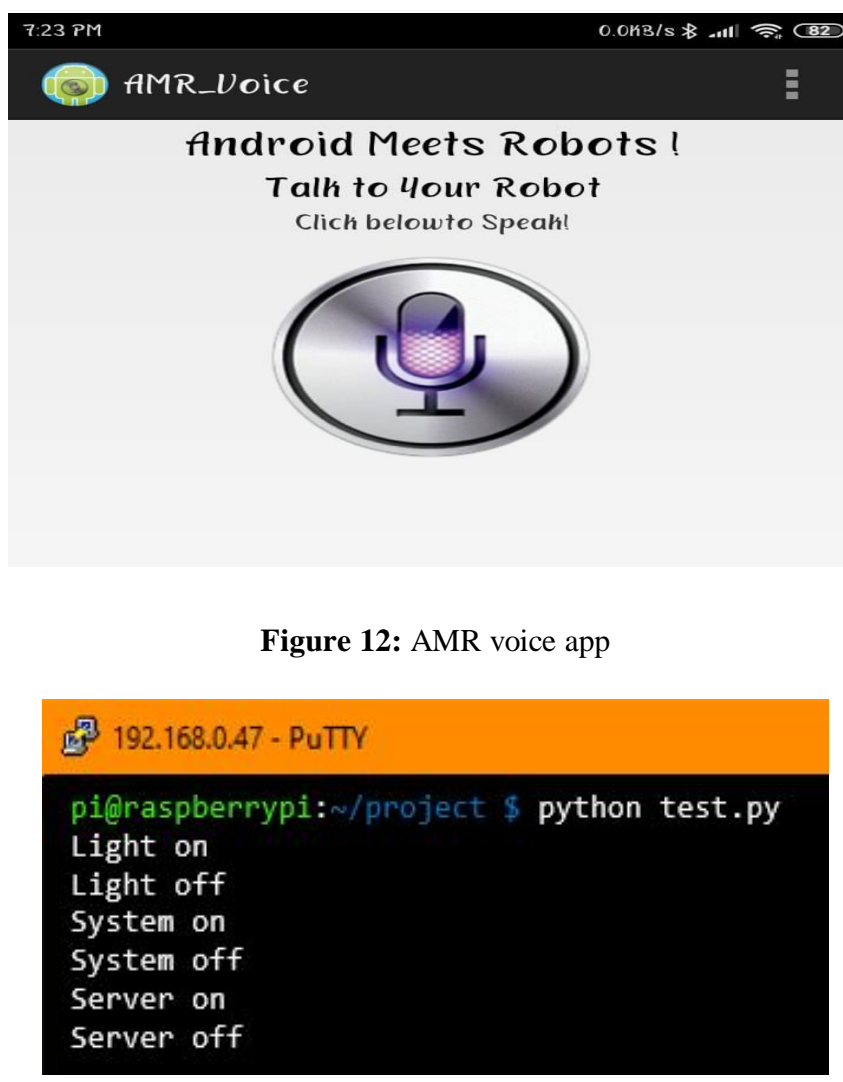

Figure 13: Controlling devices using Bluetooth

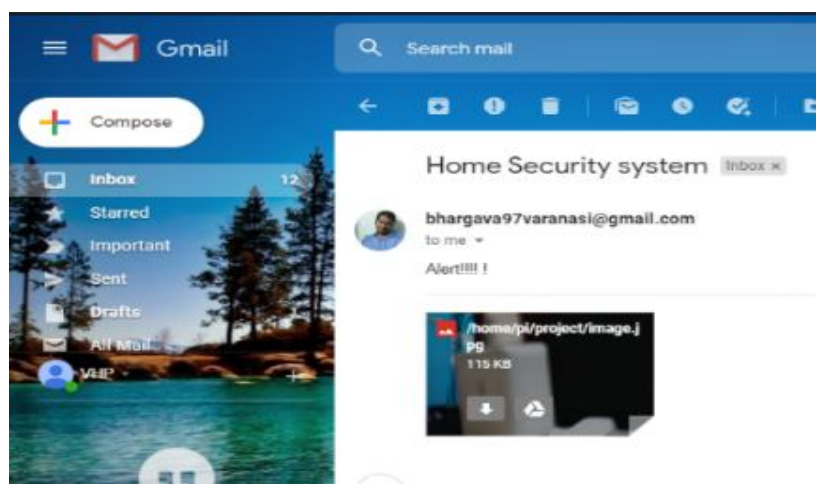

Figure 14: Email

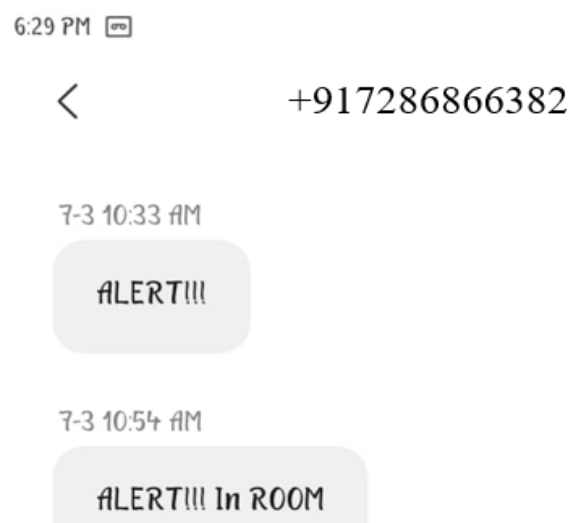

Figure 15: SMS

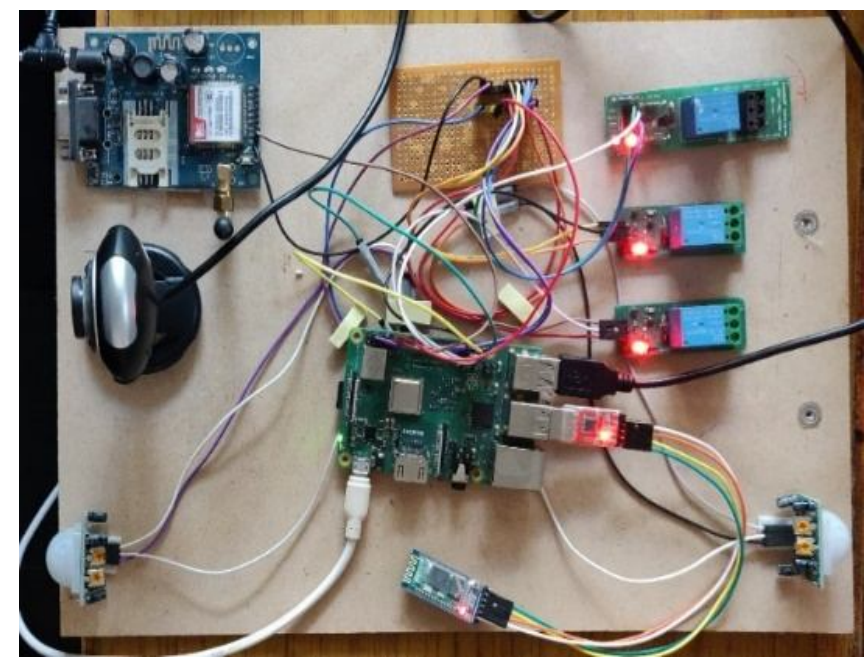

Figure 16: Prototype of the proposed system

A dashboard is also created using HTML file and is run in the browser as shown in Figure 7. Later an SMS and Email is received in the Email and mobile as shown in Figure 14 and 15.

If any intruders want to enter into home or office, then PIR sensor will detect the person and camera will captures the image of the person and that will be sent to the registered E-mail. Also, an SMS will be received by the mobile number given saying "Alert!!!” if external PIR sensor is detected and if internal PIR sensor is detected then it sends SMS saying, "Alert in room!!!". Therefore, by using these features the security can be extended. The result of the project and hardware connection is shown in below Figure 16.

\section{APPLICATIONS}

This proposed system can be used in various areas like:

- Home Automation

- Industrial Automation

- Restricted area security

- Research centers 
The security features make more feasible to use anywhere either in domestic or industrial purposes where security and automation are top priority.

\section{CONCLUSION}

The proposed system is designed to provide energy efficient secured device controller which can control the devices in a smart way by monitoring and accessing the devices from any corner of the globe and also within 100 meters using Bluetooth module using voice assistance. By using IoT device can be controlled from wherever user wants and also devices are made efficient by reducing the power consumption when not in use, also used to provide security for devices. The prototype can be even more efficient and improved security if google-assistant is added with the proposed features.

\section{REFERENCES}

1. P. Damacharla, A. Y. Javaid, J. J. Gallimore and V. K. Devabhaktuni, Common Metrics to Benchmark Human-Machine Teams (HMT): A Review, IEEE Access, vol. 6, pp. 38637-38655, 2018. https://doi.org/10.1109/ACCESS.2018.2853560

2. O. Benderius, C. Berger and V. Malmsten Lundgren, The Best Rated Human Machine Interface Design for Autonomous Vehicles in the 2016 Grand Cooperative Driving Challenge, in IEEE Transactions on Intelligent Transportation Systems, vol. 19, no. 4, pp. 1302-1307, April 2018.

3. Z. Xu, R. Wang, X. Yue, T. Liu, C. Chen and S. Fang, Face ME: Face-to-Machine Proximity Estimation Based on RSSI Difference for Mobile Industrial Human Machine Interaction, in IEEE Transactions on Industrial Informatics, vol. 14, no. 8, pp. 3547-3558, Aug. 2018. https://doi.org/10.1109/TII.2018.2829847

4. S. Ziegler, S. Nikoletsea, S. Krco, J. Rolim and J. Fernandes, Internet of Things and crowd sourcing - a paradigm change for the research on the Internet of Things, 2015 IEEE 2nd World Forum on Internet of Things (WF-IoT), Milan, 2015, pp. 395-399.

5. J. Voas, B. Agresti and P. A. Laplante, A Closer Look at IoT 's Things, in IT Professional, vol. 20, no. 3, pp. 11-14, May. /Jun. 2018.

6. Q. F. Hassan, Introduction to the Internet of Things, Internet of Things $A$ to $Z$ : Technologies and Applications, Wiley, IEEE, 2018. https://doi.org/10.1002/9781119456735

7. S. Singh and N. Singh, Internet of Things (IoT): Security challenges, business opportunities \& reference architecture for E-commerce, 2015 International Conference on Green Computing and Internet of Things (ICGCIoT), Noida, 2015, pp. 1577-1581.
8. P. Kunkun and L. Xiangong, Reliability Evaluation of Coal Mine Internet of Things, 2014 International Conference on Identification. https://doi.org/10.1109/IIKI.2014.68

9. A. J. Jara, Wearable Internet: Powering Personal Devices with the Internet of Things Capabilities, 2014 International Conference on Identification, Information and Knowledge in the Internet of Things, Beijing, 2014, pp. 7-7.

10. Q. Wang and Y. G. Wang, Research on Power Internet of Things Architecture for Smart Grid Demand, 2018 2nd IEEE Conference on Energy Internet and Energy System Integration (EI2), Beijing, 2018, pp. 1-9.

11. T. Sun, Y. Xu, J. Li and H. Zhang, Research on Internet of Things Middleware Technology for Laboratory Environmental Monitoring, 2018 International Conference on Virtual Reality and Intelligent Systems (ICVRIS), Changsha, 2018, pp. 544-547. https://doi.org/10.1109/ICVRIS.2018.00139

12. Q. F. Hassan, Internet of Things Applications for Agriculture, in Internet of Things $A$ to $Z$ : Technologies and Applications, Wiley, IEEE, 2018.

13. Y. Hsieh, Internet of Things Pillow Detecting Sleeping Quality, 2018 1st International Cognitive Cities Conference (IC3), Okinawa, 2018, pp. 266-267.

14. Q. F. Hassan, Implementing the Internet of Things for Renewable Energy, in Internet of Things $A$ to $Z$ : Technologies and Applications, Wiley, IEEE, 2018.

15. X. Li, P. Wan, H. Zhang, M. Li and Y. Jiang, The Application Research of Internet of Things to Oil Pipeline Leak Detection, 2018 15th International Computer Conference on Wavelet Active Media Technology and Information Processing (ICCWAMTIP), Chengdu, China, 2018, pp. 211-214.

16. F. A. Rachman, A. G. Putrada and M. Abdurohman, Distributed Campus Bike Sharing System Based-on Internet of Things (IoT), 2018 6th International Conference on Information and Communication Technology (ICoICT), Bandung, 2018, pp. 333-336. https://doi.org/10.1109/ICoICT.2018.8528778

17. World Energy Resources, Technical Report, World Energy Council, 2016.

18. World Energy Outlook Executive Summary, Technical Report, International Energy Agency (IEA), 2017.

19. E. Gelenbe and Y. Caseau, The impact of information technology on energy consumption and carbon emissions, Ubiquity, Association for Computing Machinery (ACM) 2015 (June), pp. 1-15.

20. Draft National Energy Policy NITI Aayog, Government of India, 2017.

21. Y. Kung, S. Liou, G. Qiu, B. Zu, Z. Wang and G. Jong, 
M. Srilatha et al., International Journal of Emerging Trends in Engineering Research, 8(5), May 2020, 1798- 1803

Home monitoring system-based internet of things, 2018 IEEE International Conference on Applied System Invention (ICASI), Chiba, 2018, pp. 325-327. https://doi.org/10.1109/ICASI.2018.8394599

22. Y. Sun, Y. Xia, H. Song and R. Bie, Internet of Things Services for Small Towns, 2014 International Conference on Identification, Information and Knowledge in the Internet of Things, Beijing, 2014, pp. 92-95.

23. D. Pavithra and R. Balakrishnan, IoT based monitoring and control system for home automation, Global Conference on Communication Technologies (GCCT), Thuckalay, 2015, pp. 169-173.

24. Edward B. Panganiban, Microcontroller-based Wearable Blood Pressure Monitoring Device with GPS and SMS Feature through Mobile App, International Journal of Emerging Trends in Engineering Research, Vol. 7, No.6, June 2019, pp. 32-35.

https://doi.org/10.30534/ijeter/2019/02762019

25. Gunawan Wang, Natanael Alamas, Marcelina Anggraeni, The use of Internet of Things and Big Data to Improve Customer Data in Insurance Company, International Journal of Emerging Trends in Engineering Research, Vol.7, No. 12, December 2019, pp. 756-761.

https://doi.org/10.30534/ijeter/2019/047122019 